\title{
Os efeitos tóxicos do antirretroviral nevirapina e um medicamento à base de nevirapina para organismos aquáticos
}

The toxic effects of the antiretroviral nevirapine and a nevirapine-based drug for aquatic organisms

Los efectos tóxicos del antirretroviral nevirapina y de um fármaco a base de nevirapina para los organismos acuáticos

Recebido: 21/12/2021 | Revisado: 07/01/2022 | Aceito: 20/01/2022 | Publicado: 22/01/2022

Juliana Souki Diniz
ORCID: https://orcid.org/0000-0003-1981-6440
Universidade Federal de Minas Gerais, Brasil
E-mail: juliana.souki@ @ahoo.com.br
Leonardo Alvarenga de Paula Freitas
ORCID: https://orcid.org/0000-0002-1401-5380
Fundação Ezequiel Dias, Brasil
E-mail: leonardo.freitas@ funed.mg.gov.br
Izabela Cristina Dias Vaz
ORCID: https://orcid.org/0000-0003-0014-8331
Universidade Federal de Minas Gerais, Brasil
E-mail: bebel.dias.vaz@ gmail.com
Francisco Antonio Rodrigues Barbosa
ORCID: https://orcid.org/0000-0001-6488-1538
Universidade Federal de Minas Gerais, Brasil
E-mail: barbosa@icb.ufmg.br
Marcos Paulo Gomes Mol
ORCID: https://orcid.org/0000-0002-2568-3579
Fundação Ezequiel Dias, Brasil
E-mail: marcos.mol@ funed.mg.gov.br
Sérgia Maria Starling Magalhães
ORCID: https://orcid.org/0000-0001-8337-403X
Universidade Federal de Minas Gerais, Brasil
E-mail: sergia.starling @ gmail.com
Micheline Rosa Silveira

\section{Resumo}

A toxicidade aquática de ingredientes ativos farmacêuticos (IFAs) e medicamentos é pouco explorada na literatura. A nevirapina (NVP) é um antirretroviral, inibidor não nucleosídeo da enzima transcriptase reversa. Este estudo avaliou a toxicidade aquática desse IFA isolado e como um medicamento à base de NVP. Para isso, foram analisados os efeitos sobre a viabilidade dos organismos aquáticos Chlorella vulgaris, Artemia salina e Aliivibrio fischeri. Foram aplicados os testes de inibição do crescimento por $72 \mathrm{~h}$ para a microalga $C$. vulgaris, de mortalidade por $24 \mathrm{~h}$ para o microcrustáceo A. salina e o de inibição da bioluminescência por $15 \mathrm{~min}$ para a bactéria $A$. fischeri. O modelo estatístico de dose-resposta não paramétrico log-logístico foi utilizado para obter as concentrações efetivas (CE) de $50 \%$ e $10 \%$ para a NVP isolada e para o medicamento. Constatou-se que a NVP isolada afetou a viabilidade das três espécies estudadas, porém, o medicamento à base de NVP não foi tóxico para A. salina. Ressalta-se que a CE50\% de NVP diferiu estatisticamente entre o IFA e o medicamento para A. fischeri e A. salina. Observou-se também que há uma estreita faixa de concentração entre o aparecimento dos primeiros efeitos observáveis e dos efeitos tóxicos de NVP nessas espécies. Isso reforça a importância do estudo e do controle de lançamento desse IFA no ambiente. Por fim, concluiu-se que é possível implementar o monitoramento da toxicidade ambiental de micropoluentes na rotina industrial, utilizando testes de toxicidade padronizados e economicamente acessíveis, que oferecem rapidez e praticidade na análise de efluentes.

Palavras-chave: Toxicidade aquática; Segurança ambiental; Ecotoxicidade; Micropoluentes. 


\begin{abstract}
The aquatic toxicity of active pharmaceutical ingredients (APIs) and drugs is little discussed in literature. Nevirapine (NVP) is an antiretroviral, non-nucleoside reverse transcriptase inhibitor. This study evaluated the aquatic toxicity of this API alone and as an NVP-based drug. For this purpose, we analyzed the effects on the viability of the aquatic organisms Chlorella vulgaris, Artemia salina and Aliivibrio fischeri. The observed effects were, per organisms: the growth inhibition tests for $72 \mathrm{~h}$ for the microalgae $C$. vulgaris; the mortality for $24 \mathrm{~h}$ for the microcrustacean $A$. salina; and the bioluminescence inhibition test for $15 \mathrm{~min}$ for the bacteria A. fischeri. The non-parametric log-logistic dose-response statistical model was used to obtain effective concentrations (EC) of 50\% and 10\%, for NVP API and for the NVP-based drug. Isolated NVP affected the viability of three studied species; on the other hand, the drug based on NVP was not toxic to A. salina. It is noteworthy that the EC50\% of NVP differed statistically between the API and the drug for A. fischeri and A. salina. It was also observed that there is a narrow concentration range between the appearance of the first observable effects and the toxic effects of NVP in these species. This reinforces the importance of studying and controlling the release of this API into the environment. Finally, it was concluded that it is possible to implement monitoring of the environmental toxicity of micropollutants in the industrial routine, using standardized and economically accessible toxicity tests, which offer speed and practicality in the analysis of effluents.
\end{abstract}

Keywords: Aquatic toxicity; Environmental safety; Ecotoxicity; Micropollutants.

\title{
Resumen
}

La toxicidad acuática de los ingredientes farmacéuticos activos (API) y los fármacos está poco explorada en la literatura. La nevirapina (NVP) es un inhibidor de la transcriptasa inversa antirretroviral no nucleósido. Este estudio evaluó la toxicidad acuática de este API solo y como un fármaco basado en NVP. Para ello, se analizaron los efectos sobre la viabilidad de los organismos acuáticos Chlorella vulgaris, Artemia salina y Aliivibrio fischeri. Se aplicaron las pruebas de inhibición del crecimiento durante $72 \mathrm{~h}$ para la microalga $C$. vulgaris, la mortalidad durante 24 h para el microcrustáceo A. salina y la prueba de inhibición de bioluminiscencia durante 15 min para la bacteria A. fischeri. Se utilizó el modelo estadístico log-logístico de dosis-respuesta no paramétrico para obtener concentraciones efetivas (CE) del 50\% y el 10\% para NVP sola y para el fármaco. Se encontró que la NVP aislada afectó la viabilidad de las tres especies estudiadas, sin embargo, el fármaco basado en NVP no fue tóxico para A. salina. Es de destacar que el CE50\% de NVP difirió estadísticamente entre el API y el fármaco para A. fischeri y A. salina. También se observó que existe un rango de concentración estrecho entre la aparición de los primeros efectos observables y los efectos tóxicos de NVP en estas especies. Esto refuerza la importancia de estudiar y controlar la liberación de este API al medio ambiente. Finalmente, se concluyó que es posible implementar el monitoreo de la toxicidad ambiental de micro contaminantes en la rutina industrial, utilizando pruebas de toxicidad estandarizadas y económicamente accesibles, que ofrecen rapidez y practicidad en el análisis de efluentes.

Palabras clave: Toxicidad acuática; Seguridad ambiental; Ecotoxicidad; Micro contaminantes.

\section{Introdução}

Os medicamentos são micropoluentes (MP) e constituem um risco à saúde pessoal, à biodiversidade e ao meio ambiente quando descartados de forma inadequada, afetando governo e sociedade (Kümmerer, 2009; Verlicchi et al. 2012; Boxall et al., 2014; Stewart et al., 2014; Hube \& Wu, 2021; González-González et al., 2022). A formulação de um medicamento é uma associação entre o ingrediente ativo farmacêutico (IFA) e os excipientes (van der Merwe et al., 2020). No ambiente, o IFA pode ser lançado de várias formas e percorrer vários caminhos, disseminado para outros ambientes ou permanecer estacionado na fonte de emissão, incorporando-se ou não aos sedimentos. A exemplo do esgoto industrial, o IFA pode ser encontrado isolado ou associado aos excipientes. Por outro lado, no esgoto doméstico, o IFA pode ser excretado de forma inalterada ou como metabólitos de sua biotransformação e excreção. A diluição e degradação são maneiras de atenuar a fonte de emissão do IFA, porém muitos deles são pouco solúveis, muito estáveis, não biodegradáveis e podem persistir no meio ambiente. De imediato, o lançamento inadequado do IFA pode contaminar os corpos hídricos locais, e ao longo do tempo pode ser carreado para rios, lagoas e até atingir os estuários, ameaçando também a vida marinha (Zakrzewski, 2002; Shea, 2004; Luo et al., 2014).

A nevirapina (NVP) é um IFA, lançado no mercado mundial pela Boehringer Ingelheim em 1996 para terapia antirretroviral (TARV). Essa substância possui características físico-químicas como baixa solubilidade em água (90 mg $\left.\mathrm{L}^{-1}\right)$, alta lipofilicidade, coeficiente de partição octanol: água (log de P) igual a 2,5, alta estabilidade à luz, à variação de pH e de temperatura (Kim et al., 2019) e baixa biodegradabilidade (Jain et al., 2013; Vaňková, 2010). Atualmente, os medicamentos à 
base de NVP são usados por cerca de trinta e cinco por cento das pessoas que vivem com o Vírus da Imunodeficiência Humana (HIV) no mundo, em especial, nos países de renda média e baixa, devido a sua eficácia e baixo custo (Gupta et al., 2016). A dose diária definida (DDD) de NVP é 200 mg e após a administração, cerca de 5\% do IFA é excretado na urina na forma inalterada (Boehringer Ingelheim, 2019).

Nesse sentido, o estudo da toxicidade aquática de NVP é relevante em função de suas propriedades químicas e das implicações do seu mecanismo de ação para organismos presentes no meio ambiente. Além disso, ressalta-se que é comum que substâncias biologicamente ativas em uma espécie induzam efeitos também em outras espécies (Kaiser, 1998). No que se refere ao seu mecanismo de ação, a inibição alostérica da transcriptase reversa (TR), enzima responsável pela polimerização das moléculas do ácido desoxirribonucleico (DNA) e do ácido ribonucleico (RNA) do HIV (Das et al., 2012), é possível que a NVP possa inibir a transcrição do DNA em outras espécies, dada a semelhança funcional entre enzimas de vias metabólicas de diferentes espécies. Cabe considerar também que NVP tem capacidade de formar complexo com vários grupos químicos (Kroeger Smith et al., 1995) e de desencadear a produção das espécies reativas de oxigênio (EROs) (Hulgan et al., 2003). Estes mecanismos inespecíficos são responsáveis por importantes efeitos adversos em humanos (del Valle et al., 2013) e podem afetar outras espécies também.

Esse estudo pretende demonstrar que é possível implementar testes de toxicidade ambiental de IFAs na rotina industrial com o uso de organismos-teste consolidados na literatura como as três espécies elencadas para o estudo. A primeira delas foi a microalga Chlorella vulgaris, uma espécie fotossintética comumente utilizada em estudos de ecotoxicidade para avaliação da toxicidade aguda e crônica (Costa et al., 2008, Nie et al., 2008; Geiger et al., 2016). Nessa espécie, a toxicidade é avaliada pela inibição do crescimento da biomassa de algas, conforme teste padronizado pela Organização para a Cooperação e Desenvolvimento Econômico (OCDE, 2011). Já a segunda espécie estudada foi o microcrustáceo Artemia salina, um consumidor primário e filtrador, cuja toxicidade aguda é avaliada pela inibição da mobilidade (mortalidade) provocada pelo MP. Por último, foi utilizada a espécie Aliivibrio fischeri, uma bactéria gram-negativa de vida livre, que possui um processo metabólico especializado capaz de dissipar energia luminosa. Este sistema é extremamente sensível à presença de substâncias que podem levar a uma redução da bioluminescência bacteriana, indicando perda da viabilidade celular (Nunes-Halldorson \& Duran, 2003; Leitão \& Silva, 2010).

Além disso, de acordo com o Sistema Globalmente Harmonizado de Classificação e Rotulagem de Produtos Químicos (GHS), a NVP inicialmente classificada como categoria de risco IV em 2017, foi reclassificada em 2019 para categoria de risco III para organismos aquáticos em função de suas características químicas. Isso evidencia que, embora os estudos de toxicidade ambiental sejam requeridos pelas agências reguladoras para registro de novos medicamentos, pouca informação se tem divulgada para apoiar a regulação de MP no ambiente aquático (BIO Intelligence Service, 2013). Nesse sentido, este artigo também pretende acrescentar informações sobre o risco de toxicidade do IFA isolado e de um medicamento à base de NVP para as três espécies aquáticas em estudo, por meio não só dos valores da CE50\%, mas também da CE10\%.

\section{Metodologia}

\subsection{Substâncias químicas}

O IFA utilizado foi a nevirapina anidra lote C5028-12009M, 100,49\%, da Zhejiang Huahai Pharmaceutical Co. Ltd (Linhai, China) e o medicamento foi o Nevirax ® 200 mg comprimidos, lote 14030011, fabricado pela Fundação Ezequiel Dias (Funed) (Belo Horizonte, Brasil). Ambos foram doados para o estudo pela Funed, aprovados pelo seu controle de qualidade. Para todas as etapas, foram utilizados reagentes e solventes grau analítico ou grau para cromatografia líquida de alta eficiência. 


\subsection{Soluções padrão para a quantificação da NVP}

Uma solução padrão de estoque foi preparada com massa de 15,82 mg do padrão de referência NVP anidra da United States Pharmacopeia (USP). A massa foi transferida para um balão volumétrico de $25 \mathrm{~mL}$ adicionando $10 \mathrm{~mL}$ de acetonitrila e $15 \mathrm{~mL}$ da água tipo I (Millipak® 20 Millipore Direct - Q® 3UV). A partir da solução estoque foram preparadas três soluções padrão de trabalho de NVP $\left(12,66 \mathrm{mg} \mathrm{L}^{-1}, 31,64 \mathrm{mg} \mathrm{L}^{-1} \mathrm{e} 63,28 \mathrm{mg} \mathrm{L}^{-1}\right)$ para a curva de calibração.

\subsection{Soluções/suspensão de NVP para testes}

A concentração analítica para NVP em cada meio de exposição foi determinada em cada solução/suspensão de trabalho e no tempo inicial do teste para o IFA e para o medicamento. Este estudo não realizou testes com IFA e o medicamento em concentrações superiores a $50,0 \mathrm{mg} \mathrm{L}^{-1}$ de NVP em função da fração solúvel previamente determinada nos meios de cultura. $\mathrm{O}$ uso de adjuvantes de solubilidade foi descartado porque alteraram os efeitos tóxicos do IFA e do medicamento nos estudos prévios, o que não é um fator desejável nos testes. As concentrações estão descritas na metodologia de cada teste.

\subsection{Meio de cultura do teste de $C$. vulgaris}

O meio de cultura BG11 (Rippka et al., 1979) foi preparado para ensaios de C. vulgaris com adição de tampão de ácido 3-morfolinopropano 1-sulfônico (MOPS) na concentração de $750 \mathrm{mg} \mathrm{L}^{-1} \mathrm{e}$ o pH foi ajustado para 8,0.

\subsection{Equipamentos e condições cromatográficas para determinação analítica da NVP}

O sistema de cromatografia líquida de ultraeficiência (UHPLC) consistiu de um Shimadzu Nexera-Prominence ${ }^{\circledR}$ UHPLC acoplado a um detector de matriz de fotodiiodo (modelo SPD-M20A), ambos da Shimadzu (Columbia, EUA). A separação foi realizada em uma coluna ShimPack XR® C18 $(2,0 \times 100 \mathrm{~mm}$, diâmetro de partículas de 2,2 $\mu \mathrm{m})$. O controle do sistema e o gerenciamento dos dados analíticos foram realizados através do software Lab Solutions®, também da Shimadzu. A água tipo I foi fase móvel A e a acetonitrila, a fase móvel B. No tempo inicial, uma mistura de $98 \%$ de fase móvel A e $2 \%$ de fase móvel B foi bombeada através da coluna a um fluxo constante de $0,25 \mathrm{~mL} \mathrm{~min}^{-1}$. Do tempo inicial ao tempo total de execução (20,0 min), um gradiente linear foi definido para atingir $2 \%$ de A e $98 \%$ de B. A temperatura da coluna foi fixada em $30 \pm 1{ }^{\circ} \mathrm{C}$. Os espectros foram obtidos para todos os picos na faixa de 190 a $800 \mathrm{~nm}$. O pico de NVP foi monitorado a $214 \mathrm{~nm}$. Uma alíquota de $3 \mathrm{~mL}$ de cada amostra foi filtrada em $0,45 \mu \mathrm{m}$ para tubos Falcon para determinação analítica da NVP no tempo inicial de teste. Em seguida, cada amostra foi transferida filtrada em $0,45 \mu \mathrm{m}$ para um frasco do amostrador automático e $3 \mu \mathrm{L}$ foram injetados no UHPLC.

\subsection{Organismos-teste}

O organismo C. vulgaris foi isolado do Parque Estadual do Rio Doce (PERD), rotulado e mantido em cultura no Laboratório de Ecologia Aquática, Ecotoxicologia e Limnologia do Instituto de Ciências Biológicas, da Universidade Federal de Minas Gerais (LIMNEA-ICB/UFMG). Os cistos dormentes de A. salina da Maramar® lote 05/2018 foram obtidos no comércio local da cidade de Belo Horizonte, Sudeste do Brasil. A biomassa liofilizada de A. fischeri (lote NRRL B-11177) foi obtida da Biolux ${ }^{\circledR}$ (Umwelt Biotecnologia Ambiental, Blumenau, Sul do Brasil), lote 151-Lyo-05.

\subsection{Testes de inibição de crescimento de C. vulgaris}

O ensaio de inibição do crescimento da biomassa de C. vulgaris foi conduzido com adaptações, de acordo com o Protocolo 201 (OCDE, 2011) por 72 h. Primeiro, o erlenmeyer contendo a cultura de C. vulgaris no meio de cultura BG11 com 
MOPS foi incubado para crescimento à temperatura de $23 \pm 2{ }^{\circ} \mathrm{C}$, fotoperíodo de $12 \mathrm{~h}$ claro/12 $\mathrm{h}$ escuro até atingir a densidade celular de aproximadamente $1,0 \mathrm{E}+07$ células $\mathrm{mL}^{-1}$. A densidade celular foi determinada pela contagem de células em microscópio óptico. Para os testes foram usadas triplicatas de erlenmeyers para cada concentração e adicionado a cada um o volume de $97 \mathrm{~mL}$ da cultura em fase de crescimento exponencial.

Antes da adição do IFA ou do medicamento ao meio de cultura, foi necessário preparar uma solução/suspensão de estoque em pH 1-2 para que se obtivesse a NVP solúvel e dessa forma fosse possível adicionar a massa requerida para cada concentração a ser testada nos meios de cultura. Para isso, ambos, o IFA e o medicamento foram preparados na mesma

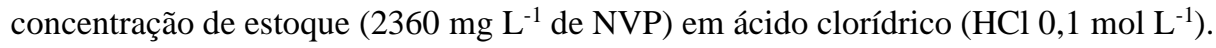

A faixa de concentração de 5,00 a 50,00 $\mathrm{mg} \mathrm{L}^{-1}$ de NVP para os testes com o IFA e com o medicamento foi determinada de acordo com a literatura e com os testes preliminares. As concentrações interpoladas foram 5,00; 10.00; 15.00; 20.00; 25.00; 30,00 e 35,00 $\mathrm{mg} \mathrm{L}^{-1}$ de NVP para o teste de determinação da CE50\% e da CE10\%.

Após adição do meio com a cultura ao erlenmeyer, adicionou-se o volume de solução/suspensão de estoque referente à massa de NVP requerida para obter a concentração a ser testada em cada triplicata. Ao final foi adicionado o volume de $\mathrm{HCl}$ $\left(0,1 \mathrm{~mol} \mathrm{~L}^{-1}\right)$ suficiente para obter $100 \mathrm{~mL}$ de cada concentração da série dentro de cada erlenmeyer.

O IFA e o medicamento foram testados concomitantemente. As triplicatas de erlenmeyers de cada concentração testada do IFA e do medicamento foram incubadas a $23 \pm 2{ }^{\circ} \mathrm{C}$, fotoperíodo de $12 \mathrm{~h}$ claro/12 $\mathrm{h}$ escuro sob luz fluorescente branca/fria de intensidade de $40-50 \mu \mathrm{mol} \mathrm{m} \mathrm{s}^{-1}$ (Du et al., 2012) e agitação a $70 \mathrm{rpm}$ por $72 \mathrm{~h}$. Os controles negativos (meio de cultura e organismo) e controle de NVP (meio e cultura e NVP) foram submetidos às mesmas condições de teste das amostras.

A densidade celular (células $\left.\mathrm{mL}^{-1}\right)$ foi determinada pela contagem celular $\left(\mathrm{N}_{0}\right.$ e $\mathrm{N}$ ) no início (T0) e no final do teste (TF) em cada erlenmeyers de cada triplicata. A taxa de crescimento $\mu$ e o percentual de inibição (I\%) foram calculados para cada concentração utilizando as seguintes equações:

$$
\begin{aligned}
& \mu=\left(\ln \mathrm{N}-\ln \mathrm{N}_{0}\right)[(\mathrm{TF}-\mathrm{T} 0)]^{-1} \\
& \mathrm{I} \%=(\mu \mathrm{T} 0-\mu \mathrm{TF})[(\mu \mathrm{T} 0)(100)]^{-1}
\end{aligned}
$$

A concentração de cada erlenmeyer e o seu respectivo percentual de inibição foram utilizados no modelo dose resposta não paramétrico log-logístico para calcular a CE50\% e a CE10\%.

\subsection{Teste de mortalidade (imobilização) de A. salina}

O método utilizado foi adaptado de Meyer et al. (1982). Primeiro, foi preparada uma solução salina a 3\% (pH 8-9). Os cistos de A. salina foram incubados em solução salina a 3\%, pH 8-9, sob luz artificial, por 36 a 48 horas, até a eclosão dos náuplios. A solução/suspensão de trabalho para os testes do IFA e do medicamento foram preparadas para obter $50 \mathrm{mg} \mathrm{L}^{-1} \mathrm{de}$ NVP em solução salina a 3\% (pH 8-9).

Optou-se por utilizar o termo concentração efetiva (CE) por englobar de forma mais ampla os três efeitos observados no estudo: a inibição do crescimento da biomassa de C. vulgaris; a imobilidade que antecede a letalidade ou a mortalidade de A. salina; e a inibição da bioluminescência de A. fischeri. A CE50\% é a concentração efetiva média de amostra que causa o efeito a 50\% dos organismos no tempo de exposição e nas condições do teste (Costa et al, 2008). A CE10\% é a concentração efetiva em que se observa o efeito em $10 \%$ dos organismos.

A faixa de concentração a ser testada foi definida com base na toxicidade da NVP descrita na literatura e nos testes preliminares. A CE50\% obtida para A. Salina foi utilizada como referência para testes com as outras espécies. As concentrações do IFA e do medicamento foram 12,67; 18.30; 23.94; 29.57; 35.20; 40,83 e 46,46 $\mathrm{mg} \mathrm{L}^{-1}$ de NVP. Os testes com o IFA e com o medicamento foram realizados concomitantemente. 
Para os testes, três tubos de controle negativo foram preparados com 5,0 mL de solução salina e 10 náuplios em cada um. Uma triplicata de tubos com o volume necessário de solução/suspensão e o volume suficiente de salina para completar 5,0 $\mathrm{mL}$ para obter cada concentração do IFA e do medicamento foi preparada; em seguida, adicionados 10 náuplios a cada um. Os tubos foram mantidos a $22{ }^{\circ} \mathrm{C}$ sob luz artificial de 1000 lux por 24h. Em seguida, o número de náuplios imóveis por pelo menos 10 segundos (ou mortos) foi contado (Nunes et al., 2006). A partir do percentual médio de náuplios imóveis (mortos) da triplicata de cada concentração, a CE50\% e a CE 10\% foram determinadas para IFA e o medicamento utilizando o modelo dose resposta não paramétrico log-logístico.

\subsection{Teste de inibição de bioluminescência de $A$. fischeri}

Os ensaios foram conduzidos em conformidade com a norma de diretrizes da Organização Internacional de Normalização, número 11348-3 (ISO, 2007). Primeiramente, uma solução salina a 2\% foi preparada para ser utilizada como diluente. Um frasco de estoque de bactéria liofilizada foi preparado adicionando $1,0 \mathrm{~mL}$ da solução de reconstituição Biolux® e foi mantido a $2^{\circ} \mathrm{C}$. A suspensão de trabalho de bactérias liofilizadas a $10 \%$ foi preparada adicionando-se $0,2 \mathrm{~mL}$ da solução de reconstituição para $2 \mathrm{~mL}$ de diluente. Ela foi mantida a $15^{\circ} \mathrm{C}$ em banho seco (Loccus® banho seco, Cotia Sudeste do Brasil).

A solução/ suspensão de trabalho do IFA e do medicamento foram preparadas para obter $50 \mathrm{mg} \mathrm{L}^{-1}$ de NVP em diluente para ajuste prévio da salinidade das amostras dos testes. A faixa de concentração para os testes foi definida com base em testes preliminares e na CE50\% de C. vulgaris e de A. salina. Foram testadas as concentrações 2,5; 5,0; 10,0; 15,0; 20,0; 25,0;30,0;35,0 $\mathrm{mg} \mathrm{L}^{-1}$ de NVP para o IFA e para o medicamento. Para o controle negativo de cada teste foi utilizado somente o diluente.

No tempo inicial, 200 microlitros de suspensão de bactérias foram adicionados aos nove tubos de ensaio mantidos banho seco a $15^{\circ} \mathrm{C}$. A bioluminescência da bactéria foi registrada no tempo inicial (T0) para todos os noves tubos pelo luminômetro Biofix ${ }^{\circledR}$ Luminometer (Macherey-Nagel, Dueren, Alemanha). Rapidamente, 800 microlitros de diluente foram adicionados ao primeiro teste do controle negativo. Aos demais tubos foram adicionados 800 microlitros de cada concentração a ser testada. Após a incubação por 15 minutos (TF) em banho seco a $15^{\circ} \mathrm{C}$, a porcentagem de inibição de bioluminescência da bactéria (I\%) foi mostrada automaticamente pelo luminômetro para cada tubo. As concentrações de cada tubo e o seus respectivos valores de I\% foram utilizados para calcular CE50\% e CE10\%.

\subsection{Análise de dados}

Os modelos de regressão estatística disponíveis na versão 3.4.2 (versão gratuita da DRC) foram utilizados na análise de dados para a avaliação da correlação entre as concentrações de NVP versus os efeitos observados (Ritz et al., 2015). O modelo dose-resposta não paramétrico log-logístico ofereceu o melhor ajuste dos dados para os três organismos. A partir das curvas dose-resposta de cada organismo para o IFA e para o medicamento foram estimados os valores de CE50\% e a CE10\% com intervalo de confiança de 95\% (IC 95\%) em um nível de significância de 5\% ( $\alpha$ 5\%).

\section{Resultados}

\subsection{CE50\% e CE 10\% do IFA isolado e do medicamento à base de NVP para C. vulgaris}

Para os testes com $C$. Vulgaris, cada amostra da série de concentração do IFA e do medicamento no meio de cultura foi caracterizada no início e após $72 \mathrm{~h}$ (tempo final de teste). Foram avaliados o aspecto, o pH e a turbidez. Verificou-se que não houve aparecimento de precipitado nas amostras dos meios de cultura contendo IFA. As mesmas se mantiveram límpidas, dentro da faixa de $\mathrm{pH}$ de 6-7 e o oxigênio dissolvido em torno de $20 \%$. O nível de turbidez dos meios de cultura expostos ao 
IFA foi semelhante ao do grupo controle. A variação na contagem de células entre o tempo inicial e o tempo final de teste mostrou que o crescimento de C. vulgaris foi inibido pelo IFA. A CE50\% e a CE10\% obtidas a partir dos dados de contagem de células ajustados ao modelo dose-resposta log-logístico foram 24,90|21,52 - 28,28| e 18,22 |13,94 - 22,50 mg L-1 de NVP, respectivamente.

Figura 1: Curva de dose-resposta para inibição de crescimento do C. vulgaris por $72 \mathrm{~h}$ pelo IFA nevirapina.

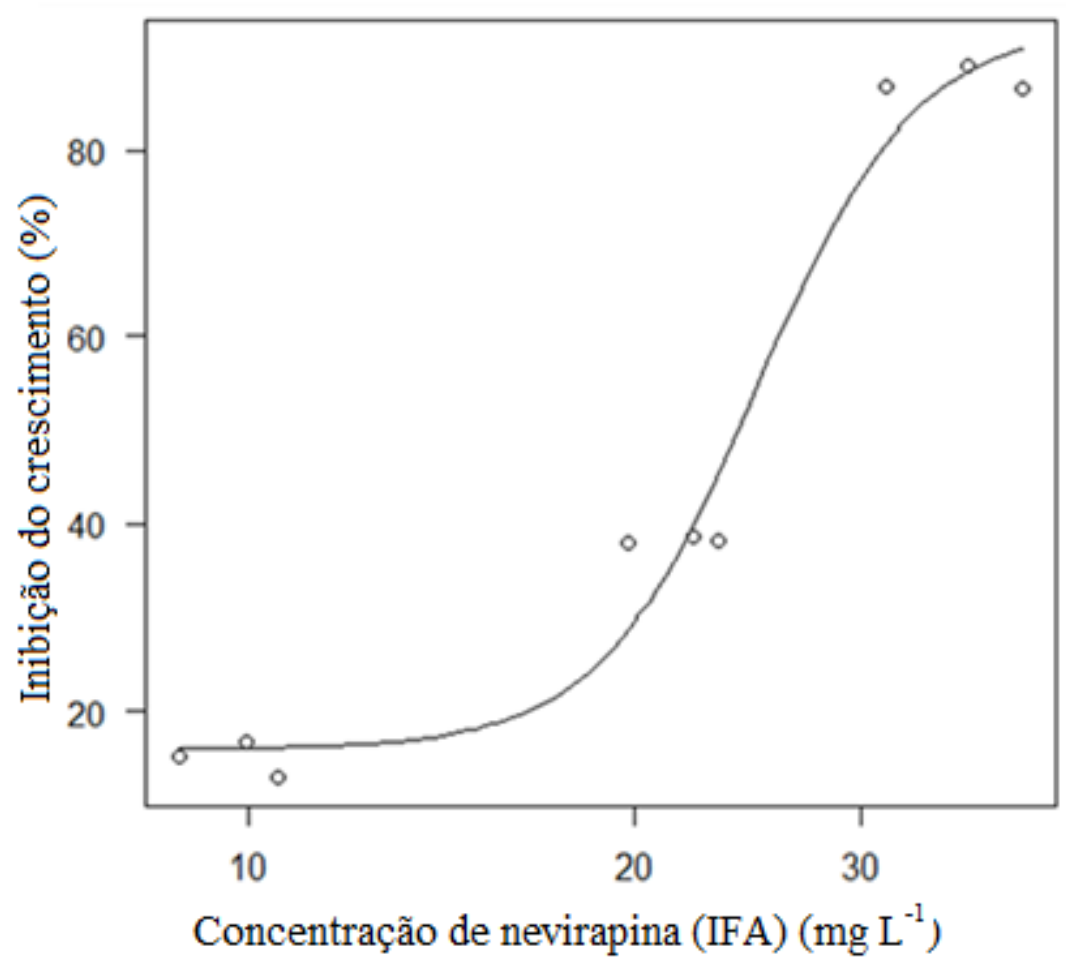

Fonte: Autores.

Como pode ser observada, a curva dose-resposta da Figura1 mostra o efeito da concentração do IFA isolado sobre a inibição do crescimento do C. vulgaris por $72 \mathrm{~h}$.

Referente aos testes com o medicamento, o nível de turbidez nessas amostras dos meios de cultura foi maior que o grupo controle em função da suspensão dos excipientes insolúveis da formulação. Porém, a turbidez não variou durante o tempo de teste. $\mathrm{O}$ pH também se manteve entre 6 e 7 e o oxigênio dissolvido em torno de $20 \%$. O método de contagem de células permitiu comparar o efeito do IFA isolado e quando associado aos excipientes (medicamento) sobre a inibição do crescimento de $C$. vulgaris. A Figura 2 mostra curva dose-resposta para inibição de crescimento de $C$. vulgaris quando exposta ao medicamento à base de NVP por $72 \mathrm{~h}$. 
Figura 2: Curva de dose-resposta para inibição de crescimento do C. vulgaris pelo medicamento à base de nevirapina por 72 h.

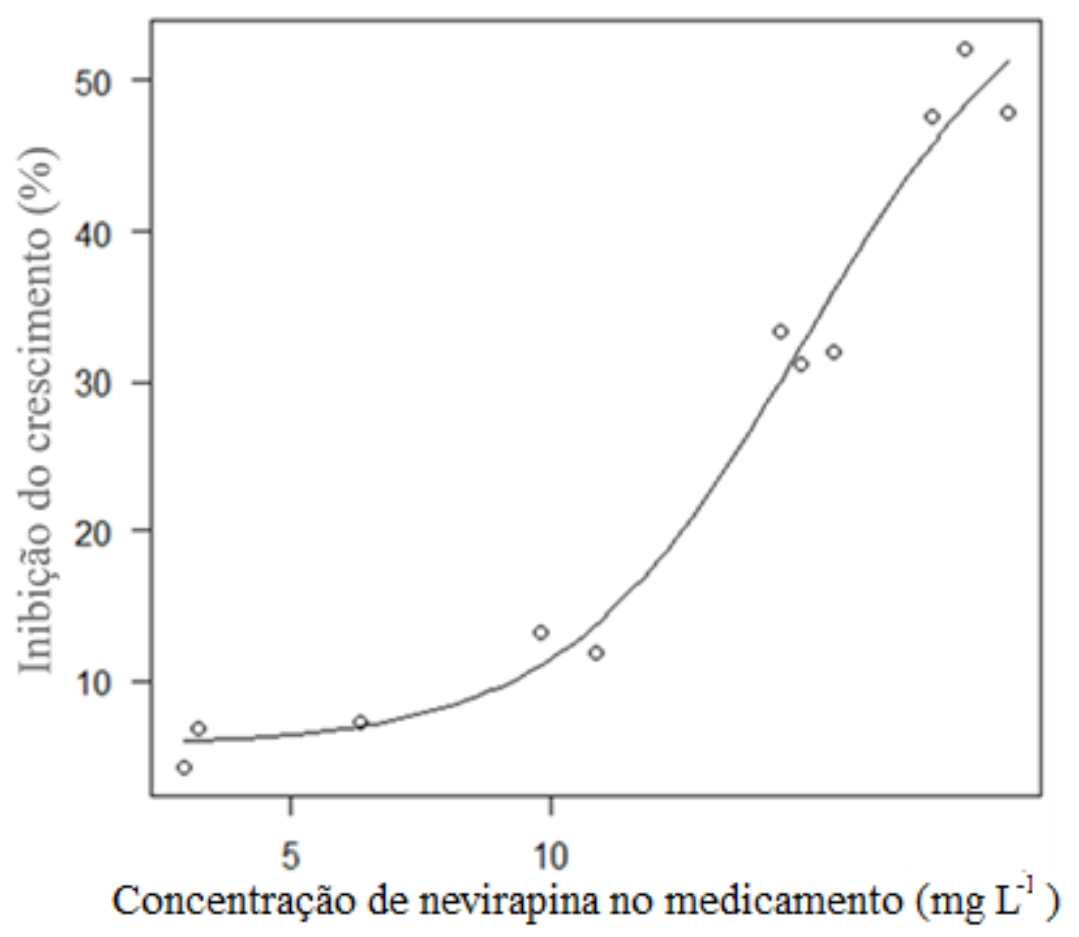

Fonte: Autores.

À mesma maneira do IFA isolado, a CE50\% e a CE10\% foram obtidas para o medicamento; os valores foram 19,52 $|13,98-25,05|$ e $9,71|5,95-13,46| \mathrm{mg} \mathrm{L}^{-1}$ de NVP, respectivamente.

\subsection{CE50\% e CE $10 \%$ do IFA isolado e do medicamento à base de NVP para A. salina}

Para o microcrustáceo A. salina, a maior concentração testada foi de 43,64 $\mathrm{mg} \mathrm{L}^{-1}$ do IFA isolado solubilizado em solução salina $3 \%$. Nesta concentração, observou-se $100 \%$ dos náuplios mortos após 72 horas de teste. Nos experimentos, não foi observada a mortalidade de náuplios quando expostos à concentração de $12,57 \mathrm{mg} \mathrm{L}^{-1}$ do IFA isolado. Os resultados foram apresentados na Tabela 1 .

Tabela 1: Média percentual de imobilidade (mortalidade) de A. salina para as concentrações médias de exposição ao IFA nevirapina por $24 \mathrm{~h}$.

\begin{tabular}{cccc}
\hline \multicolumn{2}{c}{$\begin{array}{c}\text { Concentração de NVP (IFA) } \\
\left(\mathrm{mg} \mathrm{L}^{-1}\right)\end{array}$} & \multicolumn{2}{c}{$\begin{array}{c}\text { Imobilidade (mortalidade) } \\
(\%)\end{array}$} \\
\hline $\begin{array}{c}\text { Média } \\
(\mathrm{n}=3)\end{array}$ & Desvio padrão & $\begin{array}{c}\text { Média } \\
(\mathrm{n}=3)\end{array}$ & Desvio padrão \\
\hline 12,57 & 0,70 & 0,0 & 0,0 \\
17,06 & 0,23 & 13,3 & 4,7 \\
22,4 & 0,28 & 26,7 & 4,7 \\
27,6 & 0,27 & 56,7 & 4,7 \\
33,02 & 0,25 & 76,7 & 4,7 \\
38,32 & 0,41 & 86,7 & 4,7 \\
\hline
\end{tabular}

Fonte: Autores. 
A partir das médias da contagem de náuplios imóveis (ou mortos) e da concentração média de cada triplicata (Tabela 1) foram obtidas a CE50\% (27,77|25,89-29,65| mg L ${ }^{-1}$ de NVP) e CE10\% (17,12 |15,61- 18,64| $\mathrm{mg} \mathrm{L}^{-1}$ de NVP) para o IFA isolado usando modelo log-logístico.

Referente ao medicamento, a maior concentração passível de solubilização em salina $3 \%$ foi $50,18 \mathrm{mg} \mathrm{L}^{-1}$ de NVP. Nos testes com medicamento nessa concentração, não foi observado qualquer efeito sobre a mobilidade de $A$. salina.

\section{$3.3 \%$ e CE $10 \%$ do IFA isolado e do medicamento à base de NVP para A. fischeri}

Previamente aos ensaios com A. fischeri, as soluções de trabalho/suspensões foram caracterizadas em termos de $\mathrm{pH}$, turbidez, condutividade, salinidade (Tabela 2).

Tabela 2: Caracterização das soluções de trabalho/suspensão do IFA isolado e do medicamento à base de NVP para os testes com A. fischeri.

\begin{tabular}{|c|c|c|c|c|c|c|}
\hline \multirow{2}{*}{$\begin{array}{c}\text { Solução de } \\
\text { trabalho/ } \\
\text { suspensão }\end{array}$} & \multicolumn{6}{|c|}{ Características físico-químicas } \\
\hline & $\begin{array}{c}\text { Concentração } \\
\left(m g L^{-1}\right)\end{array}$ & $p H$ & $\begin{array}{c}\text { Turbidez } \\
\text { (NTU) }\end{array}$ & Aspecto & $\begin{array}{l}\text { Salinidade } \\
\left(m g L^{-1}\right)\end{array}$ & $\begin{array}{c}\text { Oxigênio } \\
\text { dissolvido } \\
(\%)\end{array}$ \\
\hline IFA & 44,83 & 7 & 1,37 & límpido & 2,8 & 20,9 \\
\hline Medicamento & 28.59 & 6 & Maior de 1000 & turvo & 2,0 & 20,9 \\
\hline
\end{tabular}

Fonte: Autores.

A inibição da bioluminescência para cada diluição da amostra do IFA isolado e do medicamento foi registrada após o tempo de incubação de 15 min. Observou-se que o IFA isolado provocou a inibição de bioluminescência de A. fischeri conforme mostrado na curva dose-resposta da Figura 3.

Figura 3: Curva dose-resposta para inibição de bioluminescência de A. fischeri pelo IFA nevirapina por 15 min.

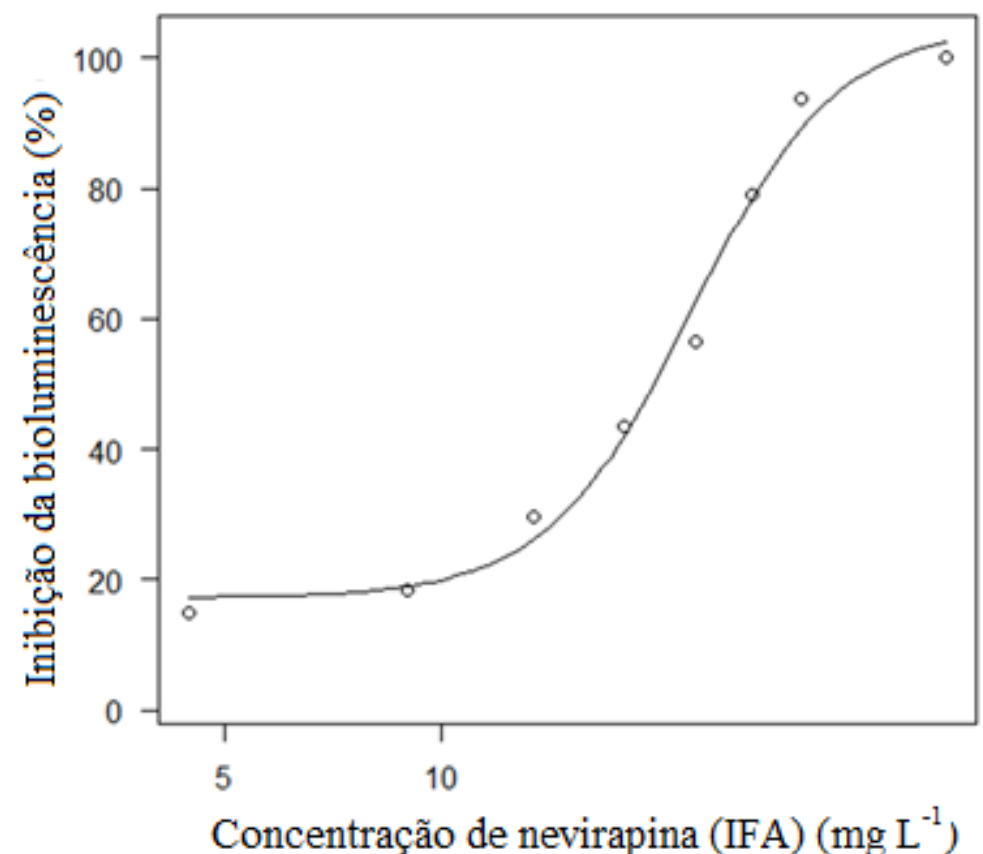

Fonte: Autores. 
A partir da curva dose-resposta obtida pelo modelo log-logístico a CE50\% estimada para o IFA foi de 22,18 |19,92 24,44 e a CE10\% foi de 13,63|10,12 - 16,61 $\mathrm{mg} \mathrm{L}^{-1}$ de NVP. Os testes e os cálculos para obtenção da CE50\% e da CE10\% do medicamento foram realizados nas mesmas condições do IFA e apresentados na Figura 4.

Figura 4: Curva dose-resposta para inibição de bioluminescência de $A$. fischeri pelo medicamento à base de nevirapina por 15 $\min$.

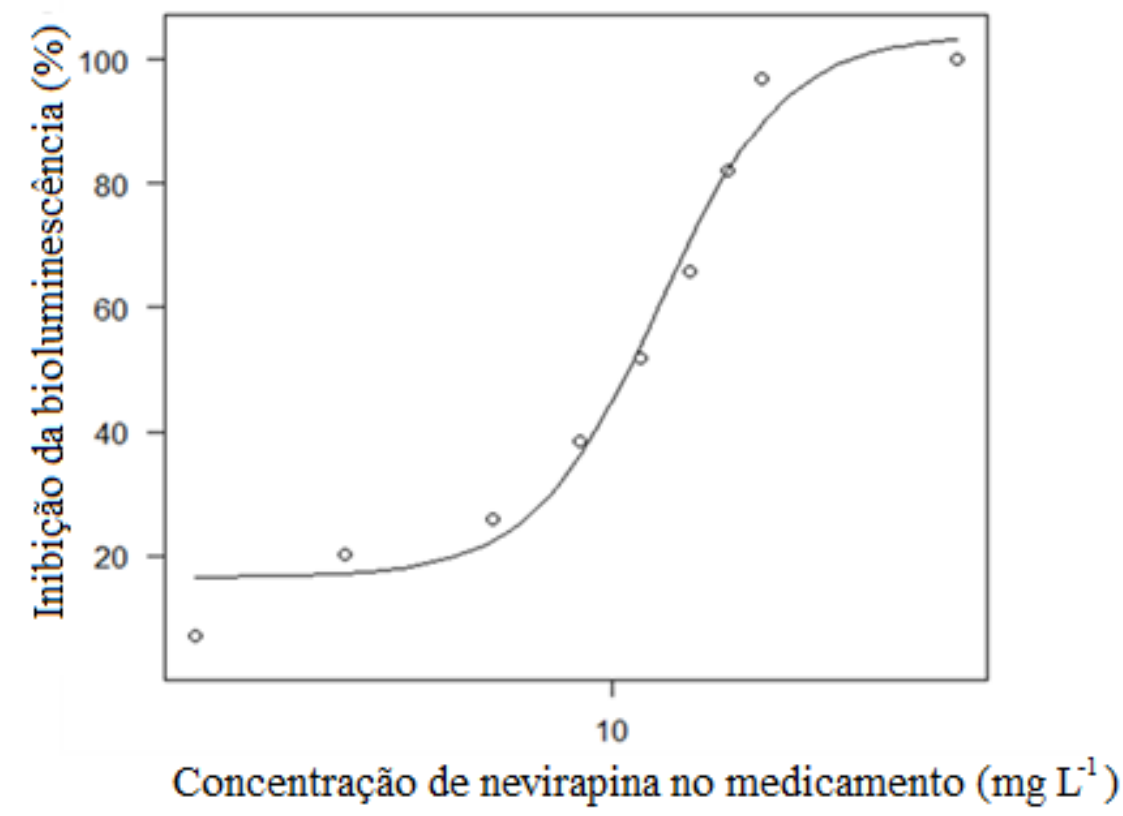

Fonte: Autores.

Foi observada a inibição da bioluminescência de A. fischeri pelo medicamento à base de NVP conforme apresentado na curva dose-resposta da Figura 4. A CE50\% foi 12,40|10,97 - 13,84 $\mathrm{mg} \mathrm{L}^{-1}$ e a CE10\% foi 6,49 |4,65-8,32 $\mathrm{mg} \mathrm{L}^{-1}$ de NVP.

\section{Discussão}

Em termos ambientais, é importante se ter um parâmetro para comparação da toxicidade aquática entre substâncias. Embora estejam sendo empreendidos esforços para se definir organismos-teste padrão, protocolos de análise e critérios de toxicidade, realização de ensaios de proficiência interlaboratoriais, ainda há alguns desafios para efetivar essa padronização, dentre os quais a diversidade de propriedades físico-químicas das substâncias testadas, o nível de objetividade da medida do efeito avaliado para o organismo-teste e a mimetização das condições do ecossistema avaliado nas condições laboratoriais (Ribo, 1997). Portanto, é fundamental que a técnica empregada não leve o pesquisador a resultados falso-positivos ou falso negativos, ora superestimando, ora mascarando a toxicidade ambiental da substância testada (Weyman et al., 2012). Com base nisso, os resultados experimentais de NVP chamam a atenção para a solubilidade do IFA que é muito afetada pela presença de outros solutos e que limitou à $50 \mathrm{mg} \mathrm{L}^{-1}$ a concentração máxima nos meios de cultura dos testes que permitia testar nas mesmas condições o IFA isolado e o medicamento à base de NVP.

Os dados da literatura sobre NVP são raros e referem-se à época do lançamento do IFA. A toxicidade ambiental de NVP foi descrita utilizando Pseudokirchnerella subcapitata (Selenastrum capricornutum) e Daphnia magna, encontrando-se os valores de 43,0 $\mathrm{mg} \mathrm{L}^{-1}$ e 76,9 $\mathrm{mg} \mathrm{L}^{-1}$ para as concentrações efetivas de NVP. (Boehringer Ingelheim, 2015). 


\subsection{Efeitos de NVP para $C$. vulgaris}

Segundo o Sistema Globalmente Harmonizado de Classificação e Rotulagem de Produtos Químicos (GHS) (2019), substâncias que apresentam CE50\% dentro da faixa de $10<\mathrm{CE} 50 \% \leq 100 \mathrm{mg} \mathrm{L}^{-1}$, oferecem risco à toxicidade aguda para microalgas e microcrustáceos. Comparando-se este parâmetro com os valores de CE50\% encontrados para o IFA isolado e para o medicamento, pode-se afirmar que a NVP não é uma substância tóxica para $C$. vulgaris.

Neste estudo, o valor da CE50\% do NVP para C. vulgaris foi duas vezes menor que a CE50\% relatada por Boehringer Ingelheim (2015) para a microalga S. Capricornutum; espécie de referência no protocolo de testes de toxicidade aquática da OECD (2011). Comparando-se as duas espécies, C. vulgaris mostrou ser um modelo mais sensível que $S$. Capricornutum para estimar o risco no ambiente aquático de NVP. Geralmente, essas variações se devem às características constitucionais específicas das espécies utilizadas, que podem ser naturalmente induzido por vias adaptativas que lhes concedem maior resistência ao xenobiótico (Li et al., 2016).

A espécie C. vulgaris foi sensível ao IFA isolado e associado à formulação, porém as CE50\% não foram estatisticamente diferentes. Considerando que apenas a fração solúvel interage diretamente com organismos aquáticos, os resultados sugeriram que os excipientes não interferiram na inibição de crescimento de $C$. vulgaris induzidas pela NVP. Embora tenha sido descrito um aumento da toxicidade das formulações de vários IFAs para microalgas $C$. vulgaris, esse efeito não se mostrou importante no caso da formulação à base de NVP. Esse resultado diverge dos relatos de Silva et al. (2014) sobre uma variação de 0,25 a $15,00 \mathrm{mg} \mathrm{L}^{-1}$ na CE50\% de cinco formulações de fluoxetina no crescimento de $C$. vulgaris em função da presença de excipientes. Cabe ressaltar a limitação do presente estudo pois o resultado refere-se a uma única formulação à base de NVP.

A microalga Chlorella vulgaris é amplamente encontrada nos ambientes de água doce, também tem sido isolada de águas de enseadas marinhas e águas salobras dos estuários (González et al., 2013; Darienko et al, 2019). Nesse estudo, a espécie mostrou facilidade de aclimatação e rápido crescimento (Li et al., 2016; Wang et al., 2018) confirmando ser uma boa ferramenta para avaliação da toxicidade aguda e crônica (Costa et al., 2008).

\subsection{Efeitos de NVP para A. salina}

A CE50\% para a espécie A. salina aponta o risco de toxicidade aguda de NVP para a espécie segundo os critérios do GHS (2019). A espécie mostrou-se um modelo sensível para estimar a toxicidade ambiental do IFA isolado, porém, para os estudos de toxicidade de matrizes complexas, é importante avaliar sua adequação do seu uso caso a caso. Nesse estudo, a presença de excipientes alterou a resposta do organismo ao teste, ainda que o nível de concentração de NVP detectado no meio de cultura tenha sido similar para os testes com IFA e ao medicamento.

A mortalidade de A. salina ocorreu em concentração de NVP três vezes menor que a descrita por Boehringer Ingelheim (2015) para o microcrustáceo de água doce D. Magna, sugerindo que para esse IFA, a espécie A. salina foi o modelo mais sensível para estimar a toxicidade (Onbasili \& Duman, 2010; Libralato et al., 2016; Oliveira et al.; 2018). Vale ressaltar que, de acordo com a literatura, comparando-se o risco tóxico entre os ARVs, em termos de CE50\%, a NVP oferece maior risco para A. salina que o abacavir (CE50\%> 100,0 $\mathrm{mg} \mathrm{L}^{-1}$ ) (Minguez et al., 2016) e que o tenofovir desoproxil (CE50\% $111,82|103,18-120,45| \mathrm{mg} \mathrm{L}^{-1}$ ) (Silva et al., 2019).

A mobilidade é fundamental para a sobrevivência de A. salina, uma vez que suas brânquias ciliadas podem não só coletar oxigênio dissolvido na água, mas também filtrar partículas de alimentos (Nunes et al., 2006). A concentração do IFA que causou $100 \%$ de mortalidade de A. salina foi apenas duas vezes maior que a CE10\%, indicando um curto intervalo entre a observação dos primeiros efeitos e o desfecho final (mortalidade). Esta observação sugere a ocorrência de um mecanismo celular de saturação rápida, tornando a espécie muito sensível ao IFA nesta faixa de concentração. Considerando que a NVP 
tem a capacidade de agir como um inibidor enzimático, é provável que enzimas relacionadas à mobilidade sejam alvo de inibição inespecífica por essa substância.

$\mathrm{O}$ uso do teste de A. salina como preditor de toxicidade de extratos vegetais e MP tem sido ressaltado em vários trabalhos, dada a boa correlação com os ensaios in vivo (Amarante et al. 2011) e in vitro (Rajabi et al., 2015). Tem sido descrito que a espécie pode ser usada para explorar a toxicidade aguda de IFAs de diferentes origens devido à sua sensibilidade às condições externas que podem comprometer sua mobilidade (Nunes et al., 2006; Lu et al., 2013; Martins et al.; 2021), corroborando os resultados desse estudo. Os testes também confirmaram sua baixa complexidade, praticidade, rapidez e facilidade de execução e de resposta (Martins et al.; 2021). Nesse sentido, essa espécie que constitui um elo entre produtores primários e organismos superiores pode ser utilizada em estudos para avaliação de bioacumulação.

\subsection{Efeitos de NVP para A. fischeri}

A bactéria A. fischeri também se mostrou sensível à NVP, porém houve diferença significativa (os intervalos de confiança não estão sobrepostos) entre as CE 50\% do IFA e do medicamento. Para esta espécie, a turbidez do meio de teste com o medicamento foi controlada conforme protocolo padrão para substâncias em suspensão. Assim, não se atribuiu exclusivamente à turbidez a diferença entre o nível de concentração de NVP do IFA e do medicamento que provocaram a inibição da bioluminescência de A. fischeri. Esse resultado é corroborado pelas observações de Jacob et al. (2016) que testou a toxicidade de dez IFAs em três diferentes formulações usando A. fischeri, demonstrando que os excipientes promovem alteração na resposta à toxicidade.

$\mathrm{Na}$ literatura foram descritos outros IFAs com o mesmo nível de concentração efetiva da NVP para inibição em 50\% da viabilidade da espécie: o diclofenaco (CE50\% 14,04 $\mathrm{mg} \mathrm{L}^{-1}$ ) (Czech et al, 2014), o metoprolol (CE50\% 14,48 $\mathrm{mg} \mathrm{L}^{-1}$ ) (de García et al., 2016), a sertralina (CE50\% de 9,2 $\mathrm{mg} \mathrm{L}^{-1}$ ) (Minagh et al., 2009) e o tenofovir (CE50\% de 14,83 $\mathrm{mg} \mathrm{L}^{-1}$ ) (Silva et al., 2019). Outros apresentaram toxicidade pouco relevante como a carbamazepina (CE50\% 78,4 $\mathrm{mg} \mathrm{L}^{-1}$ ) (Jos et al., 2003), ibuprofeno (CE50\% 75,19 $\mathrm{mg} \mathrm{L}^{-1}$ ) (Dong et al., 2019) e a azitromicina (EC50\% 237,54 $\mathrm{mg} \mathrm{L}^{-1}$ ) (Dong et al., 2019). A grande maioria dos IFAs sofrem metabolismo oxidativo. Nesse processo, pode ocorrer a transferência incompleta de pares de elétrons, formando radicais livres que geram as EROs. Entre os organismos estudados, A. fischeri foi o mais sensível à presença de NVP. A sensibilidade desse organismo à NVP, em certa medida, pode estar ligada ao complexo sistema bioquímico para produção de energia baseado em um ciclo de reações de transferência de hidrogênio que tem a enzima luciferase como intermediária da reação, que dissipa energia na forma de emissão de luz (Marques \& Silva, 2009). Segundo Leitão \& Silva (2010), interferências no ciclo de transferência de hidrogênio ou a inibição da enzima luciferase podem comprometer o processo bioluminescência. Nesse sentido, seriam interessantes estudos que pudessem avaliar a atuação de NVP nesses alvos para explicar a toxicidade desse IFA para A. fischeri. Uma possibilidade de mecanismo de ação é o estresse oxidativo, mecanismo inespecífico, que é responsável por muitos dos efeitos adversos de NVP em humanos (del Valle et al., 2013) e que pode ocorrer em outras espécies. A molécula de NVP possuir um grupo químico dipiridil que reforça esse argumento; segundo Roede \& Miller (2014), essa estrutura é precursora de espécies radicalares no metabolismo oxidativo, funcionando como aceptora de elétrons. Assim, durante o metabolismo oxidativo ocorreria um distúrbio na transferência de elétrons e seriam geradas EROs que induziriam o esgotamento do NADPH responsável pela proteção celular contra o estresse oxidativo (Awodele et al., 2015; Fernández et al., 2020), explicando a toxicidade de NVP sobre o ciclo respiratório de A. fisheri.

Cabe ressaltar que A. fisheri é uma bactéria decompositora, portanto com papel essencial para a ciclagem de nutrientes e para remoção matéria orgânica do meio aquático, nesse sentido, o comportamento de outras espécies bacterianas na presença de NVP é um problema a ser considerado, pois o efeito tóxico do NVP pode ser estendido a outras espécies decompositoras, e 
dessa maneira os processos de depuração ambiental realizados por esse grupo de organismos podem ser prejudicados (Dunn, 2012).

O teste com A. fischeri se mostrou uma ferramenta rápida, simples e altamente aplicável para o monitoramento dos efluentes urbanos e industriais (Abbas et al., 2018) como indicador da toxicidade aguda de substâncias químicas (Parvez et al., 2005).

\subsection{O efeito da formulação do medicamento sobre a toxicidade do IFA}

Para o efeito do medicamento, é necessário que o IFA esteja disponível para ser absorvido. As características biofarmacêuticas do IFA são moduladas pela adição de excipientes (van der Merwe et al., 2020); Os excipientes são considerados inertes do ponto de vista de toxicidade ambiental e são lançados no ambiente em concentrações desconhecidas (ANSES, 2013). Nesse estudo foi observado que a presença de excipientes da formulação alterou o comportamento das espécies A. salina e A. fischeri frente à NVP nas condições laboratoriais. Para a espécie C. vulgaris, exposta ao IFA e ao medicamento, não foi observada diferença estatisticamente significativa (os intervalos de confiança não estão sobrepostos) entre as concentrações efetivas de NVP que promoveram a inibição de 50\% do crescimento da sua biomassa. Por outro lado, a espécie A. salina exposta ao medicamento não foi afetada pela NVP, enquanto a espécie A. fischeri apresentou inibição da bioluminescência em concentrações efetivas mais baixas de NVP no medicamento. Embora, esses resultados evidenciem que a alteração de fatores abióticos pode favorecer a toxicidade de um IFA no meio ambiente (Shea, 2004), a presença de excipientes da formulação não alterou o nível de risco de NVP que permanece na categoria III, segundo a GHS (2019).

\subsection{Os valores de CE10\% de NVP e suas implicações}

Segundo o OECD (2011), a CE10\% é um valor estatístico mais apropriado para medir o efeito sobre as espécies porque se aproxima da concentração na qual nenhum efeito é observado (NOEC). As CE10\% para o IFA e para o medicamento apresentaram diferenças estatísticas para as espécies estudadas, o que indica que o IFA e o medicamento possuem NOEC diferentes. A presença de excipientes pode alterar fatores abióticos do meio de cultura e promover efeitos mais sutis em concentrações mais baixas de NVP. No entanto, cabe ressaltar que a razão entre os valores da CE50\% e da CE10\% para ambos, IFA e medicamento foi próxima a dois, indicando uma janela estreita entre a concentração em que são observados os primeiros efeitos e a concentração que promove efeitos inibitórios significativos sobre os processos metabólicos das espécies estudadas.

\subsection{Possíveis efeitos ambientais do IFA e do medicamento à base de NVP}

Em alguns locais em que foi consumida, detectou-se a presença de NVP em diferentes matrizes ambientais. Uma concentração de $177 \mathrm{ng} \mathrm{L}^{-1}$ foi detectada nos rios e barragens na África do Sul (Wood et al., 2015). A concentração de $410 \mathrm{ng}$ $\mathrm{L}^{-1}$ foi detectada nas águas subterrâneas no Ried e Ruhr Hessian na Alemanha (Ngumba et al., 2016). O monitoramento de NVP no Rio Nairóbi no Quênia, país de alto consumo de medicamentos ARV à base de NVP, mostrou aumento da concentração máxima detectada, passando de 510,0 ng L-1 (K'oreje et al., 2012) para 1600 ng L-1 (K'oreje et al., 2016). Segundo os autores, os níveis de concentração desse MP detectados nas matrizes testadas estavam correlacionados com a quantidade de medicamentos contendo NVP consumidos pela população local, com a adequação das condições sanitárias e com a comprovada ineficiência das estações convencionais de tratamento de água e esgoto para remover NVP (Ngumba et al., 2016; Prasse et al., 2010; K'oreje et al., 2012).

Com base no exposto, torna-se importante ressaltar que embora a CE10\% e a CE50\% sejam muito superiores às concentrações ambientais detectadas em locais com alta prevalência de uso de NVP, esses parâmetros são importantes para 
comparar os efeitos dos xenobióticos sobre as espécies e para estimar o risco deles para os diferentes estratos do ecossistema aquático. Ademais, a NVP não é um contaminante exclusivo nesses locais, é lançada continuamente a partir dos excretas humanos, é resistente à degradação e suas propriedades biofarmacêuticas favorecem seu transporte não difusivo e sua acumulação no ambiente, portanto não se pode negligenciar seu risco de afetar ecossistemas locais.

Segundo Rodrigues et al. (2018), a maioria dos estudos sobre MP são realizados pelos Estados Unidos da América, Inglaterra e Holanda, daí a contribuição desse estudo acerca da toxicidade de IFAs e medicamentos para incentivar a busca de conhecimentos mais avançados sobre um assunto que carece de investimento e apoio em especial em países em desenvolvimento.

Embora tenha sido realizado em laboratório, em condições padronizadas, utilizando substâncias de composição e pureza conhecidas, menos complexas que a matriz ambiental, é importante destacar alguns aspectos dos resultados obtidos na avaliação do IFA e do medicamento. O primeiro deles é que os resultados do estudo, em termos de CE50\% convergiram em torno da concentração de $20 \mathrm{mg} \mathrm{L}^{-1}$ de NVP, para os organismos testados apesar dos diferentes níveis de organização e complexidade celular. O segundo é que a presença de excipientes pode explicar as diferenças entre os valores obtidos para as concentrações efetivas do IFA e do medicamento para cada espécie conforme já observado nos estudos de Pavlaki et al. (2011), Silva et al. (2014) e Jacob et al. (2016), porém é necessário aprofundar nessa questão.

Pode ser apontado como um dos fatores limitantes deste estudo, a execução dos ensaios em condições controladas, o que não acontece em ambiente real. Assim, os efeitos adversos do NVP para organismos aquáticos podem ser alterados pelas múltiplas interações nesse ambiente. No entanto, a validade dos resultados obtidos está no desenho do estudo certificando a concentração real da NVP à que foram expostos os organismos nos meios de cultura e a aplicação de protocolos internacionalmente aceitos que permitiram confirmar a categorização de risco para o ambiente aquático e contribuir para o estudo de toxicidade de matrizes mais complexas contendo NVP.

\section{Conclusão}

Concluiu-se que o conhecimento de seus efeitos ambientais tóxicos de NVP se somam aos dos demais micropoluentes e que, nesse sentido é possível avançar com estudos toxicidade ambiental como forma de conhecer e dimensionar o risco ambiental decorrente da produção industrial e do consumo humano de medicamentos. Por fim, conclui-se também que o monitoramento da toxicidade ambiental desses MP é passível de implementação na rotina laboratorial, utilizando testes de toxicidade padronizados e economicamente acessíveis, que oferecem rapidez e praticidade na análise de efluentes.

\section{Agradecimentos}

Este estudo foi financiado pela Fundação de Amparo à Pesquisa e Desenvolvimento de Minas Gerais - FAPEMIG (processo n. CEX-APQ-01626-14). Os autores agradecem aos professores Doutora Liséte Celina Lange e Doutora Raquel Sampaio Jacob da Faculdade de Engenharia da UFMG pela colaboração nesse estudo. Além disso, agradecemos à equipe do Controle de Qualidade e Desenvolvimento de Medicamentos da Funed. Também agradecemos ao Luiz Gustavo de Oliveira Schenk, pela revisão gramatical dos idiomas inglês e espanhol (resumo/abstract).

\section{Declaração de financiamento}

Fundação de Amparo à Pesquisa e Desenvolvimento de Minas Gerais - FAPEMIG (processo n. CEX-APQ-0162614). 


\section{Referências}

Abbas, M., Adil, M., Ehtisham-ul-Haque, S., Munir, B., Yameen, M., Ghaffar, A., Shar, G. A., Tahir, M. A. \& Iqbal M. (2018). Vibrio fischeri bioluminescence inhibition assay for ecotoxicity assessment: A review. Sci. Total Environ. 626: 1295-1309. https://doi.org/10.1016/j.scitotenv.2018.01.066

Amarante, C. B., Müller, A. H., Póvoa, M. M. \& Dolabela, M. F. (2011) Estudo fitoquímico biomonitorado pelos ensaios de toxicidade frente à Artemia salina e de atividade antiplasmódica do caule de aninga (Montrichardia linifera). Acta Amazonica. 41, 3, 431-434. https://doi.org/10.1590/S0044$59672011000300015>$

ANSES - Agence Nationale de Securite Sanitaire. (2013). National analysis campaign on drug residues in water intended for human consumption. www.anses.fr/en/content/national-analysis-campaign-drug-residues-water-results-line-expectation.

Awodele, O., Popoola, T., Rotimi, K., Ikumawoyi, V. \& Okunowo, W. (2015). Antioxidant modulation of nevirapine induced hepatotoxicity in rats. Interdisciplinary Toxicology, 8(1), 8-14. https://doi.org/0.1515/intox-2015-0002

BIO Intelligence Service. (2013). Study on the environmental risks of medicinal products, Final Report prepared for Executive Agency for Health and Consumers.

Boehringer Ingelheim, Vetmedica. Safety data sheet United States nevirapine. Version 1. (2015). https://www.bivetmedica.com/sites/default/files/MSDS/nevirapine-sds-us.pdf

Boehringer Ingelheim, Viramune ${ }^{\circledR}$ (nevirapine) Tablets/Viramune ${ }^{\circledR} \quad$ (nevirapine) oral suspension, U.S. prescribing information. https://docs.boehringer-ingelheim.com/Prescribing\%20Information/PIs/Viramune/Viramune.pdf

Boxall, A. B. A., Keller, V. D. J., Strau, J. O., Monteiro, S. C., Fussell, R. \& Williams, R. J. (2014). Exploiting monitoring data in environmental exposure modelling and risk assessment of pharmaceuticals. Environment International, 73: 176-185. https://doi.org/10.1016/j.envint.2014.07.018.

Costa, C. R., Olivi P., Botta, C. M. R. \& Espindola, E. L. G. (2008). Toxicity in aquatic environments: Discussion and evaluation methods. Química Nova, 31: 1820-1830. https://doi.org/10.1590/S0100-40422008000700038.

Czech, B., Jośko, I. \& Oleszczuk, P. (2014). Ecotoxicological evaluation of selected pharmaceuticals to Vibrio fischeri and Daphnia magna before and after photooxidation process. Ecotoxicology and Environmental Safety, 104: 247-253. https://doi.org/10.1016/j.ecoenv.2014.03.024

Darienko, T., Rad-Menéndez, C., Campbell, C., \& Pröschold, T. (2019). Are there any true marine Chlorella species? Molecular phylogenetic assessment and ecology of marine Chlorella-like organisms, including a description of Droopiella gen. nov. Systematics and Biodiversity, 17(8), 811-829. https://doi.org/10.1080/14772000.2019.1690597

Das, K., Martinez, S. E., Bauman, J. D. \& Arnold, E. (2012). HIV-1 reverse transcriptase complex with DNA and nevirapine reveals non-nucleoside inhibition mechanism. Nature Structural \& Molecular Biology, 19: 253-259. https://doi.org/10.1038/nsmb.2223

de García, S. O., García-Encina, P. A. \& Irusta-Mata, R. (2016). Dose-response behavior of the bacterium Vibrio fischeri exposed to pharmaceuticals and personal care products. Ecotoxicology, 25: 141- 790 162. https://doi.org/10.1007/s10646-015-1576-8

del Valle, L. G., Hernández, R. G. \& Ávila, J. P. (2013). Oxidative stress associated to disease progression and toxicity during antiretroviral therapy in human immunodeficiency virus infection. Journal of Virology \& Microbiology, 2013, 279685, 15. https://doi.org/10.5171/2013.279685

Dong, Y., Fang, Z., Xu, Y., Wang, Q. \& Zou, X. (2019). The toxic effects of three active pharmaceutical ingredients (APIs) with different efficacy to Vibrio fischeri. Emerg. Contam. 5: 297-302. https://doi.org/10.1016/j.emcon.2019.08.004

Du, J., Yuan, Y., Si, T., Lian, J. \& Zhao, H. (2012). Customized optimization of metabolic pathways by combinatorial transcriptional engineering. Nucleic Acids Research, 40: 142. https://doi.org/10.1093/nar/gks549

Dunn, A. K. (2012). Vibrio fischeri metabolism: symbiosis and beyond. Advances in microbial physiology, 61: 37-68. https://doi.org/10.1016/B978-0-12394423-8.00002-0

Fernández, L. P., Brasca, R., Attademo, A. M., Peltzer, P. M., Lajmanovich, R. C. \& Culzoni, M. J. (2020). Bioaccumulation and glutathione S-transferase activity on Rhinella arenarum tadpoles after 813 short-term exposure to antiretrovirals. Chemosphere, $246 . \quad 125830$ https://doi.org/10.1016/j.chemosphere.2020.125830

Geiger, E., Gausterer, R. H. \& Saçan, M. T. (2016). Single and mixture toxicity of pharmaceuticals and chlorophenols to freshwater algae Chlorella vulgaris. Ecotoxicology and Environmental Safety, 129: 189-198. https://doi.org/10.1016/j.ecoenv.2016.03.032

GHS (2019) Globally Harmonized System of Classification and Labelling of Chemicals. Eighth Revised Edition, United Nations, New York, https://doi.org/10.18356/f8fbb7cb-en

González, M. A., Proschold, T., Palacios, Y., Aguayo, P., Inostroza, I., \& Gomez, P. I. (2013). Taxonomic identification and lipid production of two Chilean Chlorella-like strains isolated from a marine and an estuarine coastal environment. AoB Plants, 5(0), plt020-plt020. https://doi.org/10.1093/aobpla/plt020

González-González, R. B., Sharma, A., Parra-Saldívar, R., Ramirez-Mendoza, R. A., Bilal, M. \& Iqbal, H. M. N. (2022). Decontamination of emerging pharmaceutical pollutants using carbon-dots as robust materials. J Hazard Mater. 5; 423 (Pt B):127145. https://doi.org/1010.1016/j.jhazmat.2021.127145.

Gupta, B. P., Lama, T. K., Adhikari, A., Shrestha, A., Rauniyar, R., Sapkota, B., Thapa, S., Shrestha, S., Gupta, P. P. \& Manandhar, K. D. (2016). First report of hepatitis E virus viremia in healthy blood donors from Nepal. Virus Disease, 27: 324-326. https://doi.org/10.1007/s13337-016-0331-y

Hube, S. \& Wu, B. (2021) Mitigation of emerging pollutants and pathogens in decentralized wastewater treatment processes: A review, Science of The Total Environment, 779,146545. https://doi.org/10.1016/j.scitotenv.2021.146545 
Hulgan, T., Morrow, J., D’Aquila, R. T., Raffanti, S., Morgan, M., Rebeiro, P. \& Haas, D. W. (2003). Oxidant stress is increased during treatment of human immunodeficiency virus infection. Clinical Infectious Diseases, 37:1711-7. https://doi.org/10.1086/379776

ISO 11348-3. (2007) Water quality - determination of the inhibitory effect of waste samples on the light emission of Vibrio fischeri (luminescent bacteria test) - part 3: method using freeze-dried bacteria. Geneva. International Organization for Standardization.

Jacob, R. S., Santos, L. V., Souza, A. F. \& Lange, L. C. (2016). A toxicity assessment of 30 pharmaceuticals using Aliivibrio fischeri: a comparison of the acute effects of different formulations. Environmental tecnology, 37: 2760-2767. https://doi.org/10.1080/09593330.2016.1164249

Jain, V., Hartogensis, W., Bacchetti, P., Hunt, P. W., Hatano, H., Sinclair, E., Epling, L., Lee, T. H., Busch, M. P., McCune, J. M., Pilcher, C. D., Hecht. F. M. \& Deeks, S. G. (2013). Antiretroviral therapy initiated within 6 months of HIV infection is associated with lower T-cell activation and smaller HIV reservoir size. J. Infect. Dis, 208: 1202-1211. https://doi.org/10.1093/infdis/jit311.

Jos, A., Repetto, G., Rios, J. C., Hazen, M. J., Molero, M. L., del Peso, A., Salguero, M., Fernández-Freire, P., Pérez-Martín, J. M. \& Cameán A. (2003). Ecotoxicological evaluation of carbamazepine using six different model systems with eighteen endpoints. Toxicology in Vitro, 17: 525-532. https://doi.org/10.1016/S0887-2333(03)00119-X

Kaiser, L. E. (1998). Correlations of vibrio fischeri bacteria test data with bioassay data for other organisms. Environmental Health Perspectives, 106 (2). 583591. https://doi.org/10.1289/ehp.98106583

Kim, S., Chen, J., Cheng, T., Gindulyte, A., He, J., He, S., Li, Q., Shoemaker, B. A., Thiessen, P. A., Yu, B., Zaslavsky, L., Zhang, J. \& Bolton, E. E. (2019). PubChem 2019 update: improved access to chemical 871 data. Nucleic acids research, 47: 1102-1109. https://doi.org/10.1093/nar/gky1033

K'oreje, K. O., Demeestere, K., De Wispelaere, P., Vergeynst, L., Dewulf, J., Van Langenhove, H. (2012). From multi-residue screening to target analysis of pharmaceuticals in water: Development of a new approach based on magnetic sector mass spectrometry and application in the Nairobi River basin, Kenya. Sci. Total Environ. 437: 153-164. https://doi.org/10.1016/j.scitotenv.2012.07.052

K'oreje, K.O., Vergeynst, L., Ombaka, D., De Wispelaere, P., Okoth, M., Van Langenhove, H. \& Demeestere, K. (2016). Occurrence Patterns of Pharmaceutical Residues in Wastewater, Surface Water and Groundwater of Nairobi and Kisumu City, Kenya. Chemosphere, 149: 238-244. https://doi.org/10.1016/j.chemosphere.2016.01.095

Kroeger, M. B. S., Rouze, C. A., Taneyhill, L. A., Smith, N. A., Hughes, S. H., Boyer, P. L., Janssen, P. A. J., Moereels, H., Koymans, L., Arnold, E., Ding, J., Das, K., Zhang, W., Michejda, C. J. \& Smith Jr, R. H. (1995). Molecular modeling studies of HIV-1 reverse transcriptase nonnucleoside inhibitors: Total energy of complexation as a predictor of drug placement and activity. Protein Science, 4:2203-2222. https://doi.org/10.1002/pro.5560041026

Kümmerer, K. (2009). Antibiotics in the aquatic environment - A review - Part I. Chemosphere, 75: 417-434. https://doi.org/10.1016/j.Chemosphere.2008.11.086

Leitão, J. M. M. \& Silva, J. C. G. E. (2010). Firefly luciferase inhibition. Journal of Photochemistry and Photobiology B: Biology, 101: 1-8. https://doi.org/10.1016/j.jphotobiol.2010.06.015

Li, T., Xu, G., Rong, J., Chen, H., He, C., Giordano, M., Wang, Q. (2016). The acclimation of Chlorella to high-level nitrite for potential application in biological NOx removal from industrial flue gases. Journal of Plant Physiology, 195: 73-79. https://doi.org/10.1016/j.jplph.2016.03.006

Libralato, G., Prato, E., Migliore, L., Cicero, A. \& Manfra, L. (2016). A review of toxicity testing protocols and endpoints with Artemia spp. Ecolological Indicators, 69: 35-49. https://doi.org/10.1016/j.ecolind.2016.04.017

Lu, Y., Xu, X., Meng, C., Zhou, J., Sheng, J., Wu, C. \&, Xu, S. (2013). The toxicity assay of Artemia salina as a biological model for the preliminary toxic evaluation of chemical pollutants. Advanced Materials Research, 726-731, 230-233. https://doi.org/10.4028/www.scientific.net/AMR.726-731.230

Luo, Y., Guo, W., Ngo, H. H., Nghiem, L. D., Hai, F. I., Zhang, J., Liang, S. \& Wang, X. C. (2014). A review on the occurrence of micropollutants in the aquatic environment and their fate and removal during wastewater treatment. Science of The Total Environment, 473-474, 619641. https://doi.org/10.1016/j.scitotenv.2013.12.065.

Marques, S. M. \& Silva, J. C. G. E. (2009). Firefly bioluminescence: A mechanistic approach of luciferase catalyzed reactions. IUBMB Life, 61: 6-17. https://doi.org/10.1002/iub.134

Martins, A. C. R., da Costa, J. K. N., Herbert, A., Farias, F. R. S., Rezende, M., Kozlowski Junior, V. A. \& de Geus, J. L. (2021) Toxicity assessment of mastic and pomegranate tinctures using the Artemia salina bioassay. Research, Society and Development, [S. 1.], 10, 3, e5201031375. https://doi.org/10.33448/rsd-v10i3.13751.

Meyer, B., Ferrigni, N., Putnam, J., Jacobsen, L., Nichols, D. \& McLaughlin, J. (1982). Brine Shrimp: A Convenient General Bioassay for Active Plant Constituents. Planta Medica, 45: 31-34. https://doi.org/10.1055/s-2007-971236

Minagh, E., Hernan, R., O'Rourke, K., Lyng, F. M. \& Davoren, M. (2009). Aquatic ecotoxicity of the selective serotonin reuptake inhibitor sertraline hydrochloride in a battery of freshwater test species. Ecotoxicology and environmental safety, 72: 434-440. https://doi.org/10.1016/j.ecoenv.2008.05.002

Minguez, L., Pedelucq, J., Farcy, E., Ballandonne, C., Budzinski, H. \& Halm-Lemeillz, M. P. (2016). Toxicities of 48 pharmaceuticals and their freshwater and marine environmental assessment in northwestern France. Environmental Science and Pollution Research, 23 : 4992-5001. https://doi.org/10.1007/s11356-014-3662-5

Ngumba, E., Gachanja, A. \& Tuhkanen, T. (2016). Occurrence of selected antibiotics and antiretroviral drugs in Nairobi River Basin, Kenya. Science of the Total Environ, 539: 206-213. https://doi.org/10.1016/j.scitotenv.2015.08.139

Nie, X., Wang, X., Chen, J., Zitko, V. \& An T. (2008). Response of the freshwater alga Chlorella vulgaris to trichloroisocyanuric acid and ciprofloxacin. Environmental Toxicology and Chemistry, 27: 168-173. https://doi.org/10.1897/07-028.1 
Nunes-Halldorson, V. S. \& Duran, N. L. (2003). Bioluminescent bacteria: lux genes as environmental biosensors. Braz. J. Microbiol., 34: 91-96. https://doi.org/10.1590/S1517-83822003000200001

Nunes, B. S., Carvalho, F. D., Guilhermino, L. M. \& Van Stappen, G. (2006). Use of the genus Artemia in ecotoxicity testing. Environmental pollution, 144: 453-462. https://doi.org/10.1016/j.envpol.2005.12.037

Oliveira, G. A. R., Leme, D. M., de Lapuente, J., Brito, L. B., Porredón, C., Rodrigues, L. B., Brull, N., Serret, J. T., Borràs, M., Disner, G. R., Cestari, M. M. \& Oliveira, D. P. (2018). A test battery for assessing the ecotoxic effects of textile dyes. Chem Biol Interact. 1;291:171-179. https://doi.org/10.1016/j.cbi.2018.06.026.

Onbasili, D. \& Duman, F. (2010). Acute toxicity of some insecticides on Artemia salina and Daphnia magna. Fresenius Environmental Bulletin. 19 (11): $2608-2610$

Organisation for Economic Co-operation and Development - OECD. (2011). Guidelines for testing chemicals freshwater alga and cyanobacteria growth inhibition test. 201. Retrived from https://www.oecd-ilibrary.org/docserver/9789264069923-en.pdf?expi

Parvez, B. S., Venkataraman, C. \& Mukherji, S. (2005). A review on advantages of implementing luminescence inhibition test (Vibrio fischeri) for acute toxicity prediction of chemicals. Environment International, 32, 265 - 268. https://doi.org/10.1016/j.envint.2005.08.022

Pavlaki, M. D., Pereira, R., Loureiro, S. \& Soares, A. M. (2011). Effects of binary mixtures on the life traits of Daphnia magna. Ecotoxicology and environmental safety, 74: 99-110. https://doi.org/10.1016/j.ecoenv.2010.07.010

Prasse, C., Schlüsener, M. P., Schulz, R. \& Ternes, T. A. (2010). Antiviral Drugs in Wastewater and Surface Waters: A New Pharmaceutical Class of Environmental Relevance? Environmental science \& technology, 44: 1728-1735. https://doi.org/10.1021/es903216p

Rajabi, S., Ramazani, A., Hamidi, M. \& Naji, T. (2015) Artemia salina as a model organism in toxicity assessment of nanoparticles. DARU J Pharm Sci 23, 20. https://doi.org/10.1186/s40199-015-0105-x

Ribo, J. M. (1997). Interlaboratory Comparison Studies of the Luminescent Bacteria Toxicity. Bioassay. Environmental Toxicology and Water Quality, 12(4), 283-294. Retrived 2020, from https://jglobal.jst.go.jp/en/detail?JGLOBAL_ID=200902141905826462

Rippka, R., Deruelles, J. \& Waterbury, J. B. (1979). Generic Assignments, Strain Histories and Properties of Pure Cultures of Cyanobacteria. Journal of sant General Microbiology, 111: 61. https://doi.org/10.1099/00221287-111-1-1

Ritz, C., Baty, F., Streibig, J. C. \& Gerhard, D. (2015). Dose-Response Analysis Using R. PLoS ONE, 10: e0146021. https://doi.org/10.1371/journal.pone.0146021

Rodrigues, M. O., Gonçalves, A. M. M.,Gonçalves, F. J. M., Nogueira, H., Marques, J. C. \& Abrantes, N.(2018). Effectiveness of a methodology of microplastics isolation for environmental monitoring in freshwater systems, Ecological Indicators, 89: 488-495, https://doi.org/10.1016/j.ecolind.2018.02.038.

Roede, J. R. \& Miller, G. W. 2014. Diquat. Encyclopedia of Toxicology, 2. 202-204. http://dx.doi.org/10.1016/B978-0-12-386454-3.00137-8

Shea, D. (2004). Transport and Fate of Toxicants in the Environment. A Textbook of Modern Toxicology, 479-499. https://doi.org/10.1002/0471646776.ch27

Silva, A., Santos, L. H., Delerue-Matos, C.\& Figueiredo, A. S. 2014. Impact of excipients in the chronic toxicity of fluoxetine on the alga Chlorella vulgaris. Environmental technology, 35: 3124-3129. https://doi.org/10.1080/09593330.2014.932438

Silva, S. R., Barbosa, F. A. R., Mol, M. P. G., Magalhães, S. M. S. (2019). Toxicity for Aquatic Organisms of Antiretroviral Tenofovir Disoproxil. Journal of Environmental Protection, 10: 1565-1577. https://doi.org/10.4236/jep.2019.1012093

Stewart, M., Olsen, G., Hickey, C. W., Ferreira, B., Jelić, A., Petrović, M., \& Barcelo, D. (2014).A survey of emerging contaminants in the estuarine receiving environment around Auckland, New Zealand. Science of The Total Environment, 468-469, 202-210. https://doi.org/10.1016/j.scitotenv.2013.08.039:

van der Merwe, J., Steenekamp, J., Steyn, D. \& Hamman, J. (2020). The Role of Functional Excipients in Solid Oral Dosage Forms to Overcome Poor Drug Dissolution and Bioavailability. Pharmaceutics, 12, 393. https://doi.org/10.3390/pharmaceutics12050393

Vaňková, M. (2010). Biodegradability analysis of pharmaceuticals used in developing countries; screening with OxiTop ${ }^{\circledR}$ - C $11073 f .$, Doctoral thesis. Tampere University of Applied Sciences, Finland

Verlicchi, P., Al Aukidy, M., \& Zambello, E. (2012). Occurrence of pharmaceutical compounds in urban wastewater: removal, mass load and environmental risk after a secondary treatment - a review. Science of the total environment, 429, 123-155. https://doi.org/10.1016/j.scitotenv.2012.04.028

Wang, L., Wang, H., Chen, X., Zhuang, Y., Yu, Z. \& Zhou, T. (2018). Acclimation process of cultivating Chlorella vulgaris in toxic excess sludge extract and its response mechanism. The Science of the total environment, 628-629, 858-869. https://doi.org/10.1016/j.scitotenv.2018.02.020

Weyman, G. S., Rufli, H., Weltje, L., Salinas, E. R. \& Hamitou, M. (2012). Aquatic toxicity tests with substances that are poorly soluble in water and consequences for environmental risk assessment. Environmental toxicology and chemistry, 31: 1662-1669. https://doi.org/10.1002/etc.1856

Wood, T. P., Duvenage, C. S. J. \& Rohwer, E. (2015). The occurrence of anti-retroviral compounds used for HIV treatment in South African surface water. Environmental pollution, 199: 235-243. https://doi.org/10.1016/j.envpol.2015.01.030

Zakrzewski, S. F. (2002). Environmental toxicology. Oxford University Press. 